\title{
Pengaruh Financial Attitude, Financial Behavior, Financial Knowledge, dan Risk Tolerance terhadap Financial Satisfaction
}

\author{
Olivia Sandra Wijaya dan Ary Satria Pamungkas \\ Program Studi Manajemen Fakultas Ekonomi \& Bisnis \\ Universitas Tarumanagara \\ Email : oliviawijaya23@gmail.com
}

\begin{abstract}
The purpose of this study is to examine the effect of Financial Attitude, Financial Behavior, Financial Knowledge and Risk Tolerance on Financial Satisfaction. The sample in this study is all residents who already have income or income in the Jakarta area. The sample was chosen by the non-probability sampling method, amounting to 190 respondents by distributing questionnaires online. The data analysis technique used is Structural Equation Modeling (SEM) which is assisted with the assistance of the Smart-PLS program.3.3.2. The results of this study are that there is a positive influence of Financial Attitude on Financial Satisfaction, there is a positive influence of Financial Behavior on Financial Satisfaction, and there is a positive influence of Financial Knowledge on Financial Satisfaction. While the results obtained in this study indicate there is no effect of Risk Tolerance on Financial Satisfaction.
\end{abstract}

Keywords : Financial Attitude, Financial Behavior, Financial Knowledge, Risk Tolerance, Financial Satisfaction.

Abstrak : Tujuan dari penelitian ini adalah untuk meneliti mengetahui pengaruh Financial Attitude, Financial Behavior, Financial Knowledge dan Risk Tolerance terhadap Financial Satisfaction. Sampel pada penelitian ini adalah seluruh penduduk yang sudah memiliki pendapatan atau penghasilan di wilayah Jakarta. Sampel dipilih dengan metode non-probability sampling yang berjumlah 190 responden dengan penyebaran kuesioner secara online. Teknis analisis data digunakan adalah Structural Equation Modeling (SEM) yang dibantu dengan bantuan program Smart-PLS.3.3.2. Hasil dari penelitian ini adalah terdapat pengaruh positif Financial Attitude terhadap Financial Satisfaction, terdapat pengaruh positif Financial Behavior terhadap Financial Satisfaction, dan terdapat pengaruh positif Financial Knowledge terhadap Financial Satisfaction. Sedangkan hasil yang didapat pada penelitian ini menunjukkan tidak terdapat pengaruh Risk Tolerance terhadap Financial Satisfaction.

Kata Kunci : Financial Attitude, Financial Behavior, Financial Knowledge, Risk Tolerance, Financial Satisfaction.

\section{LATAR BELAKANG}

Tujuan keuangan penting dalam merencanakan bagaimana seseorang mengelola keuangannya untuk mencapai kepuasan keuangan yang lebih baik. Dalam ilmu keuangan, seseorang dapat merasakan kebahagiaan apabila telah terpenuhi Financial Satisfaction (kepuasan keuangan). Menurut Hira dan Mugenda (1998), Financial Satisfaction (kepuasan keuangan) merupakan penerapan dari kebiasaan hidup individu sebagai ukuran kesejahteraan subjektif (subjective well-being). Hasil survei yang dilakukan oleh salah satu asuransi di Indonesia (Manulife Investor Sentiment Index Study, 2016) menunjukkan kekecewaan investor dalam 
mengelola keuangan semakin diperburuk dengan terus melakukan kebiasaan yang berulang menuju kerugian. Menemukan beberapa hal yaitu, (a)40 persen pekerja individu tidak memantau pengeluaran sama sekali setiap bulan. (b)53 persen pekerja individu menghabiskan lebih dari 70 persen penghasilan dalam setiap bulan. (c)70 persen pekerja individu tidak memiliki target dana simpanan untuk jangka panjang. Penelitian tersebut melibatkan 511 responden sudah memiliki dana tunai sendiri, berusia 25 tahun serta menyeselaikan sekolah menengah atas atau lebih, dari tiga kota Jakarta, Surabaya dan Medan.

Dengan kata lain membuktikan masyarakat Indonesia adalah masyarakat konsumtif. Hal tersebut juga merupakan salah satu masalah pada kepuasan keuangan, sebab seseorang tidak memiliki tujuan rencana keuangan yang jelas untuk jangka panjang atau mempersiapkan masa pensiun, dan tidak peduli terhadap kondisi keuangannya. Seharusnya individu yang baik menyimpan atau menambah aset keuangan yang dimiliki, untuk tujuan keuangan yang jelas.Berdasarkan data yang dilakukan Otoritas Jasa Keuangan (OJK) tingkat indeks inklusi keuangan masyarakat Indonesia masih lebih rendah dibandingkan dengan negara sekitar, pada tahun 2019 menunjukkan indeks literasi keuangan mencapai 38,03 persen dan indeks inklusi keuangan 76,19 persen. Hal ini masih jauh dibandingkan dengan tingkat inklusi keuangan masyarakat Malaysia mencapai 85 persen dan tingkat inklusi keuangan masyarakat Singapura mencapai 98 persen. Sehingga dengan peristiwa seperti ini penduduk masyarakat Indonesia belum sepenuhnya mempunyai pengetahuan yang baik mengenai bagaimana seharusnya mengoptimalkan sumber daya keuangan yang dimiliki untuk mensejahterakan kondisi keuangannya. Alasan peneliti memilih menelitian Financial Satisfaction (kepuasan keuangan) dari penduduk Jakarta karena terkait dengan adanya pandemi virus corona yang membuat dampak pendapatan atau penghasilan dari penduduk Jakarta menjadi berkurang banyak terutama para pekerja dan wirausaha (Sindonews, 2020). Terdapat beberapa faktor yang mempengaruhi Financial Satisfaction seseorang, diantaranya adalah Financial Attitude, Financial Behavior, Financial Knowledge, dan Risk Tolerance.

\section{KAJIAN TEORI}

Subjective Well-Being Theory. Menurut Diener (2003) mendefinisikan Subjective Well-being adalah suatu keadaan yang didapatkan dari menggabungkan antara aspek afektif dan kognitif. Aspek afektif yang diharapkan untuk meraih subjective well-being adalah perasaan bahagia akan hidupnya, sedangkan aspek kognitif yang diharapkan adalah individu mempunyai pemilikiran bahwa berbagai aspek kehidupan terpenuhi. Kepuasan keuangan berkaitan dengan tingkat kebahagiaan dan kesejahteraan keuangan maupun kondisi keuangan yang baik (Gerrans et al. 2013).

Theory of Planned Behavior. Merupakan teori mengenai rasionalitas pada individu dalam berperilaku, juga adanya keyakinan bahwa target tingkah laku berada di bawah kesadaran dari individu. Theory of Planned Behavior menjelaskan bahwa perilaku individu akan muncul dikarenakan adanya tujuan untuk berperilaku, yang secara khusus pada perilaku yang detail. Faktor dalam Theory of Planned Behavior adalah tujuan individu dalam melakukan suatu sikap tertentu. Tujuan tersebut dibentuk untuk mencakup faktor motivasi yang mempengaruhi suatu perilaku (Jugiyanto, 2007). 
Financial Attitude. Menurut penelitian Chowa et al (2012) mendefinisikan Financial Attitude sebagai pandangan, pikiran, pendapat terhadap subjek keuangan yang dicerminkan ke dalam perilaku sikap. Financial Attitude mengarah pada keyakinan dan nilai yang terkait dengan konsep keuangan pribadi, seperti seseorang mempercayai bahwa menghemat uang itu penting atau tidak.

Financial Behavior. Menurut penelitian Ahmad et al (2017) menyatakan bahwa Financial Behavior (perilaku keuangan) mengacu pada manajemen keuangan yang sistematis seperti melakukan penghematan secara konsisten dan rencanakan tujuan keuangan yang ingin dicapai.

Financial Knowledge. Menurut penelitian Chen dan Volpe (1998) mendefinisikan Financial Knowledge (pengetahuan keuangan) sebagai wawasan ilmu dasar keuangan serta mengaplikasikannya dengan benar dalam mengelola dan mengambil keputusan keuangan secara tepat. Dengan kata lain, pengambilan keputusan keuangan yang tepat agar menghindari terjadinya kesulitan atau masalah keuangan dimasa yang akan datang.

Risk Tolerance. Menurut Joo et al (2004) mendefinisikan Risk Tolerance sebagai besarnya maksimum individu dapat menerima ketidakpastian bahwa seseorang bersedia menghadapai kondisi ketika membuat keputusan keuangan, mencapai ke hampir setiap bagian dari kehidupan sosial dan ekonomi.

Financial Satisfaction. Merupakan suatu gambaran umum yang menyatakan bagaimana kondisi keuangan seseorang yang sehat serta orang tersebut merasa bahagia dan bebas dari rasa khawatir terhadap kondisi keuangan pribadi (Joo \& Grabel, 2004).

Financial Attitude terhadap Financial Satisfaction. Menurut penelitian yang dilakukan oleh Chandra dan Memarista (2015) menunjukkan bahwa Financial Attitude dapat berpengaruh terhadap Financial Satisfaction. Financial Attitude (sikap keuangan) yang dilakukan dengan benar, seperti menyisihkan uang setiap bulan untuk ditabung apabila memiliki kelebihan dana yang dimiliki, akan berdampak positif terhadap kondisi keuangan pribadi, sehingga dapat meningkatkan Financial Satisfaction (kepuasan keuangan). Penelitian yang dilakukan oleh Falahati et al. (2012) menunjukkan bahwa Financial Attitude berpengaruh signifikan terhadap Financial Satisfaction. Financial Attitude dapat menentukan sikap dan perilaku serta pengambilan keputusan dalam mengelola keuangan. Terdapat motivasi semangat seseorang terhadap tindakan kepuasan keuangan, ketika seseorang memiliki pandangan untuk mengelola keuangan dengan benar dan tepat maka tujuan Financial Satisfaction (kepuasan keuangan) akan lebih tercapai.

Financial Behavior terhadap Financial Satisfaction . Penelitian yang dilakukan oleh Arifin (2018) menyatakan bahwa terdapat pengaruh yang signifikan Financial Behavior terhadap Financial Satisfaction. Semakin baik Financial Behavior (perilaku keuangan) seseorang maka kepuasan seseorang terhadap kondisi keuangannya akan semakin baik juga. Seseorang yang memiliki Financial Behavior yang baik akan memiliki Financial Satisfaction yang tinggi. Maka, seseorang akan memperoleh kepuasan dari hasil mengelola keuangan, mampu membeli barang sesuai dengan keinginan, dan bertanggung jawab untuk menyisihkan sebagian penghasilan untuk kebutuhan yang akan datang. Penelitian yang dilakukan oleh Saurabh dan Nandan (2018) 
menunjukkan bahwa terdapat pengaruh yang signifikan antara Financial Behavior terhadap Financial Satisfaction. Sikap yang dimiliki oleh seseorang terhadap pengelolaan dan mengatur keuangannya dapat mempengaruhi perilaku yang dimiliki oleh individu tersebut. Perilaku yang dimiliki seseorang dalam mengelola dan mengatur keuangannya akan memberikan pengaruh terhadap kepuasan keuangan dalam kehidupannya.

Financial Knowledge terhadap Financial Satisfaction. Penelitian yang dilakukan oleh Chandra et al. (2015) serta Xiao et al. (2014) menyatakan bahwa Financial Knowledge berpengaruh positif terhadap Financial Satisfaction. Individu yang telah memiliki Financial Knowledge yang cukup baik akan mempunyai Financial Satisfaction yang lebih baik, sehingga akan berdampak bagi kondisi keuangan individu yang pada akhirnya akan meningkatkan tingkat Financial Satisfaction individu tersebut. Dalam penelitian yang dilakukan oleh Yap et al. (2016) diperoleh hasil bahwa terdapat pengaruh Financial Knowledge terhadap Financial Satisfaction. Hal ini karena selain memiliki Financial Knowledge, juga didukung oleh kesadaran yang besar akan pentingnya membuat dasar perencanaan keuangan dan pengaturan penggunaan atau pemakaian uang secara bijak dalam jangka panjang, agar keinginan dan kebutuhan hidup masa depan dapat dipenuhi dengan menggunakan dana secara efektif, maka akan memberikan hasil individu merasa puas dengan kondisi keuangan mereka.

Risk Tolerance terhadap Financial Satisfaction. Menurut penelitian yang dilakukan oleh Jeong dan Hanna (2004) menyatakan bahwa terdapat pengaruh yang positif Risk Tolerance terhadap Financial Satisfaction. Semakin besar Risk Tolerance yang dimiliki individu, maka memberi pengaruh semakin besar pula tingkat kepuasan terhadap keadaan keuangannya. Menurut penelitian yang dilakukan oleh Sahi dan Kalra (2013) menyatakan bahwa tidak terdapat pengaruh Risk Tolerance terhadap Financial Satisfaction. Pada tingkat standar hidup seseorang untuk Risk Tolerance tidak dapat disamakan dengan tingkat kehidupan seseorang pada saat ini, dikarenakan tingkat Financial Satisfaction (kepuasaan keuangan) seseorang tidak memadai, ditambah jumlah tanggungan yang harus dipenuhi. Perbedaan ini dapat menyebabkan perubahan pada tingkat Financial Satisfaction (kepuasan keuangan).

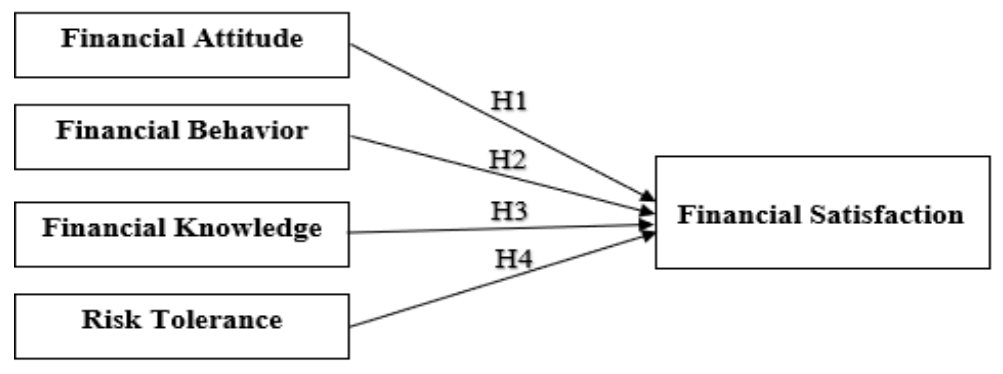

Gambar 1. Kerangka Pemikiran

Berdasarkan konsep teori model yang dibangun di atas, maka hipotesis dalam penelitian ini sebagai berikut:

H1 : Terdapat pengaruh Financial Attitude terhadap Financial Satisfaction.

H2 : Terdapat pengaruh Financial Behavior terhadap Financial Satisfaction.

H3 : Terdapat pengaruh Financial Knowledge terhadap Financial Satisfaction.

H4 : Terdapat pengaruh Risk Tolerance terhadap Financial Satisfaction. 


\section{METODOLOGI}

Populasi dalam penelitian ini adalah seluruh penduduk yang sudah memiliki pendapatan atau penghasilan di wilayah Jakarta. Apabila terdapat responden yang tidak memenuhi syarat, maka responden tidak dapat melanjutkan pengisian kuesioner penelitian ini. Tujuannya adalah agar data yang diperoleh menjadi lebih representatif. Teknik yang dipakai dalam pemilihan sampel penelitian ini adalah dengan bantuan Google Form yang disebarkan secara online. Teknik analisis data yang digunakan adalah Structural Equation Modeling (SEM) yang dibantu dengan bantuan program Smart-PLS.3.3.2. Suatu model penelitian harus memenuhi syarat valid dan reliabel, sehingga pada penelitian ini model akan diuji validitas dan reliabilitasnya. Setelah sebuah model penelitian memenuhi persyaratan uji model pengukuran (outer model analysis) maka tahap selanjutnya adalah melakukan analisis model struktural (inner model analysis) penelitian kriteria-kriteria yang harus dipenuhi dalam analisis model struktural meliputi nilai koefisien determinasi $\left(\mathrm{R}^{2}\right)$, predictive relevance $\left(\mathrm{Q}^{2}\right)$, effect size $\left(\mathrm{f}^{2}\right)$ dan path coeffcients. Pada penelitian yang menggunakan PLS-SEM, maka pengujian hipotesis dilakukan dengan melihat nilai t-statistik dari sampel independen.

\section{HASIL UJI STATISTIK}

Tabel 1. Hasil Analisis Average Variance Extracted (AVE)

\begin{tabular}{|c|c|}
\hline Variabel & AVE \\
\hline Financial Attitude & 0,504 \\
\hline Financial Behavior & 0,502 \\
\hline Financial Knowledge & 0,570 \\
\hline Risk Tolerance & 0,558 \\
\hline Financial Satisfaction & 0,557 \\
\hline
\end{tabular}

Tabel 1 menunjukkan bahwa nilai AVE dari variabel Financial Satisfaction, Financial Attitude, Financial Behavior, Financial Knowledge, dan Risk Tolerance telah mencapai di atas 0,5 yang berarti sudah memenuhi kriteria convergent validity yang dilihat dari kriteria nilai AVE.

Tabel 2. Nilai Loading Factor

\begin{tabular}{|c|c|c|c|c|c|}
\hline Indikator & $\begin{array}{c}\text { Financial } \\
\text { Attitude }\end{array}$ & $\begin{array}{c}\text { Financial } \\
\text { Behavior }\end{array}$ & $\begin{array}{c}\text { Financial } \\
\text { Knowledge }\end{array}$ & $\begin{array}{c}\text { Risk } \\
\text { Tolerance }\end{array}$ & $\begin{array}{c}\text { Financial } \\
\text { Satisfaction }\end{array}$ \\
\hline FA1 & 0.718 & & & & \\
\hline FA2 & 0.753 & & & & \\
\hline FA3 & 0.711 & & & & \\
\hline FA4 & 0.777 & & & & \\
\hline FA5 & 0.571 & & & & \\
\hline FB1 & & 0.702 & & & \\
\hline FB2 & & 0.748 & & & \\
\hline FB3 & & 0.746 & & & \\
\hline FB4 & & 0.692 & & & \\
\hline FB5 & & 0.672 & & & \\
\hline FB6 & & 0.642 & & & \\
\hline
\end{tabular}


Olivia dan Ary: Pengaruh Financial Attitude, Financial Behavior, Financial...

\begin{tabular}{|l|l|l|l|l|l|}
\hline FB7 & & 0.749 & & \\
\hline FK1 & & & 0.805 & & \\
\hline FK2 & & & 0.668 & & \\
\hline FK3 & & & 0.743 & & \\
\hline FK4 & & & 0.797 & & \\
\hline RT1 & & & & 0.616 & \\
\hline RT2 & & & & 0.694 & \\
\hline RT3 & & & & 0.818 & \\
\hline RT4 & & & & 0.769 & \\
\hline RT5 & & & & 0.819 & \\
\hline FS1 & & & & & 0.715 \\
\hline FS2 & & & & & 0.777 \\
\hline FS3 & & & & & 0.790 \\
\hline FS4 & & & & & 0.797 \\
\hline FS5 & & & & & 0.777 \\
\hline FS6 & & & & & \\
\hline
\end{tabular}

Tabel 2, menunjukkan bahwa nilai Loading Factor dari variabel Financial Attitude, Financial Behavior, Financial Knowledge, Risk Tolerance, dan Financial Satisfaction telah mencapai di atas 0,5 yang berarti sudah memenuhi kriteria convergent validity.

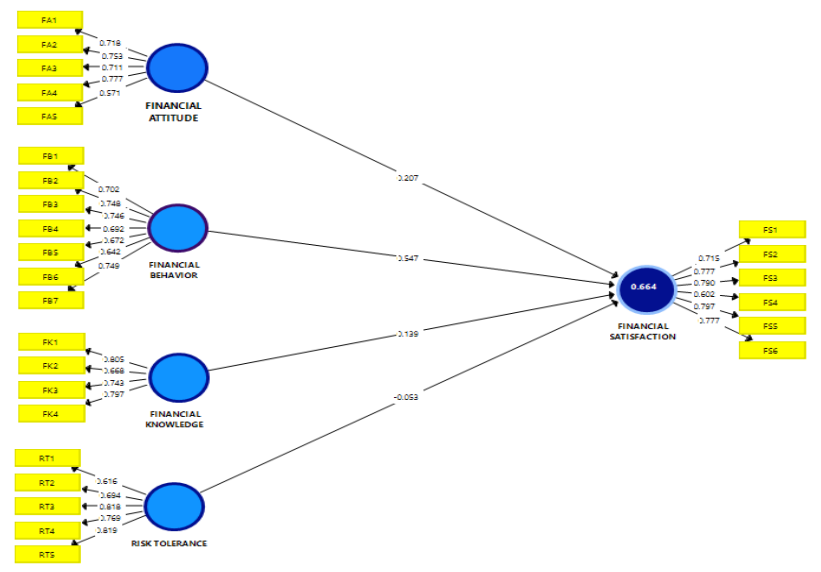

Gambar 2. Hasil Gambar Convergent Validity

Tabel 3. Hasil nilai Cross Loadings

\begin{tabular}{|l|r|r|r|r|r|}
\hline & $\begin{array}{l}\text { Financial } \\
\text { Attitude }\end{array}$ & $\begin{array}{l}\text { Financial } \\
\text { Behavior }\end{array}$ & $\begin{array}{l}\text { Financial } \\
\text { Knowledge }\end{array}$ & $\begin{array}{l}\text { Financial } \\
\text { Satisfaction }\end{array}$ & $\begin{array}{l}\text { Risk } \\
\text { Tolerance }\end{array}$ \\
\hline FA1 & 0.718 & 0.528 & 0.478 & 0.548 & -0.309 \\
\hline FA2 & 0.753 & 0.517 & 0.405 & 0.489 & -0.121 \\
\hline FA3 & 0.711 & 0.435 & 0.29 & 0.433 & -0.136 \\
\hline FA4 & 0.777 & 0.566 & 0.50 & 0.521 & -0.142 \\
\hline
\end{tabular}


Olivia dan Ary: Pengaruh Financial Attitude, Financial Behavior, Financial...

\begin{tabular}{|l|r|r|r|r|r|} 
FA5 & 0.571 & 0.369 & 0.244 & 0.368 & -0.053 \\
\hline FB1 & 0.560 & 0.702 & 0.339 & 0.467 & -0.310 \\
\hline FB2 & 0.554 & 0.748 & 0.453 & 0.579 & -0.299 \\
\hline FB3 & 0.542 & 0.746 & 0.483 & 0.596 & -0.281 \\
\hline FB4 & 0.443 & 0.692 & 0.250 & 0.480 & -0.320 \\
\hline FB5 & 0.445 & 0.672 & 0.358 & 0.561 & -0.262 \\
\hline FB6 & 0.418 & 0.642 & 0.270 & 0.482 & -0.268 \\
\hline FB7 & 0.448 & 0.749 & 0.408 & 0.575 & -0.308 \\
\hline FK1 & 0.455 & 0.429 & 0.805 & 0.478 & -0.218 \\
\hline FK2 & 0.372 & 0.365 & 0.668 & 0.334 & -0.134 \\
\hline FK3 & 0.298 & 0.318 & 0.743 & 0.350 & -0.160 \\
\hline FK4 & 0.518 & 0.456 & 0.797 & 0.474 & -0.07 \\
\hline FS1 & 0.437 & 0.533 & 0.359 & 0.715 & -0.210 \\
\hline FS2 & 0.553 & 0.638 & 0.455 & 0.777 & -0.374 \\
\hline FS3 & 0.468 & 0.630 & 0.400 & 0.790 & -0.262 \\
\hline FS4 & 0.293 & 0.450 & 0.257 & 0.602 & -0.216 \\
\hline FS5 & 0.558 & 0.623 & 0.475 & 0.797 & -0.330 \\
\hline FS6 & 0.547 & 0.530 & 0.481 & 0.777 & -0.146 \\
\hline RT1 & 0.007 & -0.181 & 0.033 & -0.145 & 0.616 \\
\hline RT2 & -0.098 & -0.302 & -0.099 & -0.278 & 0.694 \\
\hline RT3 & -0.256 & -0.378 & -0.202 & -0.307 & 0.818 \\
\hline RT4 & -0.236 & -0.333 & -0.202 & -0.315 & 0.769 \\
\hline RT5 & -0.165 & -0.274 & -0.155 & -0.188 & 0.819 \\
\hline
\end{tabular}

Tabel 3, menunjukkan bahwa nilai cross loading dari masing-masing indikator untuk setiap variabel lebih besar dibandingkan dengan variabel lainnya. Hal ini menunjukkan bahwa indikator-indikator tersebut telah memenuhi kriteria discriminant validity yang diukur dari nilai cross loadings.

Tabel 4. Hasil Analisis Fornell-Lacker

\begin{tabular}{|c|c|c|c|c|c|}
\hline Variabel & $\begin{array}{c}\text { Financial } \\
\text { Attitude }\end{array}$ & $\begin{array}{c}\text { Financial } \\
\text { Behavior }\end{array}$ & $\begin{array}{c}\text { Financial } \\
\text { Knowledge }\end{array}$ & $\begin{array}{c}\text { Financial } \\
\text { Satisfaction }\end{array}$ & $\begin{array}{c}\text { Risk } \\
\text { Tolerance }\end{array}$ \\
\hline Financial Attitude & 0.710 & & & & \\
\hline Financial Behavior & 0.689 & 0.708 & & & \\
\hline Financial Knowledge & 0.555 & 0.526 & 0.755 & & \\
\hline Financial Satisfaction & 0.673 & 0.655 & 0.552 & 0.746 & \\
\hline Risk Tolerance & -0.226 & -0.411 & -0.191 & -0.352 & 0.747 \\
\hline
\end{tabular}

Tabel 4, menunjukkan bahwa nilai akar kuadrat AVE setiap variabel lebih besar dari korelasi antar variabel telah memenuhi kriteria Fornell-Larcker Hal ini menunjukkan bahwa variabel-variabel tersebut memenuhi discriminant validity. 
Olivia dan Ary: Pengaruh Financial Attitude, Financial Behavior, Financial...

Tabel 5. Hasil Analisis Reabilitas

\begin{tabular}{|c|c|c|}
\hline Variabel & Cronbach's Alpha & Composite Reliability \\
\hline Financial Attitude & 0.751 & 0.834 \\
\hline Financial Behavior & 0.834 & 0.875 \\
\hline Financial Knowledge & 0.751 & 0.841 \\
\hline Financial Satisfaction & 0.839 & 0.882 \\
\hline Risk Tolerance & 0.804 & 0.862 \\
\hline
\end{tabular}

Tabel 5, menunjukkan bahwa nilai Cronbach's Alpha untuk setiap variabel lebih dari 0,7 dan menunjukkan nilai Composite Reliability untuk semua variabel di atas 0,7. Hal tersebut menunjukkan bahwa semua variabel pada model ini sudah memenuhi kriteria dari uji reliabilitas.

Tabel 6. Hasil pengujian Koefisien Determinasi $\left(\mathrm{R}^{2}\right)$

\begin{tabular}{|c|c|}
\hline Variabel & R Square \\
\hline Financial Satisfaction & 0.664 \\
\hline
\end{tabular}

Tabel 6, menunjukkan bahwa nilai dari $R$ square sebesar 0,664 yang berarti bahwa sebesar $66,4 \%$ dari variabel dependen (Financial Satisfaction) dapat dijelaskan melalui variabel Financial Attitude, Financial Behavior, Financial Knowledge, dan Risk Tolerance dalam penelitian ini, dan sisanya sebesar 33,6\% dapat dijelaskan oleh variabel-variabel yang ada di luar penelitian ini. Nilai $R$ square dalam penelitian ini sebesar 0,664 dapat dinyatakan tergolong moderate.

Tabel 7. Hasil Bootstrapping

\begin{tabular}{|l|r|r|r|}
\hline & Path Coefficients & t-statistic & p-values \\
\hline Financial Attitude $\rightarrow$ Financial Satisfaction & 0.207 & 2.958 & 0.003 \\
\hline Financial Behavior $\rightarrow$ Financial Satisfaction & 0.547 & 8.869 & 0.000 \\
\hline Financial Knowledge $\rightarrow$ Financial Satisfaction & 0.139 & 2.549 & 0.011 \\
\hline Risk Tolerance $\rightarrow$ Financial Satisfaction & -0.053 & 1.393 & 0.164 \\
\hline
\end{tabular}

Berdasarkan hasil pengujian dari bootstrapping yang telah disajikan pada Gambar 2 dan Tabel 7. maka persamaan dalam penelitian ini sebagai berikut: $\mathrm{FS}=0,207 \mathrm{FA}+0,547 \mathrm{FB}+$ 0,139FK - 0,053RT. Melalui persamaan di atas, menunjukkan bahwa nilai Path Coefficients dari variabel Financial Attitude terhadap Financial Satisfaction memiliki arah positif yaitu sebesar 0,207, nilai Path Coefficients dari variabel Financial Behavior terhadap Financial Satisfaction memiliki arah positif yaitu sebesar 0,547, nilai Path Coefficients dari variabel Financial Knowledge terhadap Financial Satisfaction memiliki arah positif yaitu sebesar 0,139, dan nilai Path Coefficients dari variabel Risk Tolerance terhadap Financial Satisfaction memiliki arah negatif sebesar 0,053 .

Menunjukkan bahwa variabel Financial Attitude memiliki nilai t-statistik sebesar 2,958 yang lebih besar dari 1,96 dan nilai Path Coefficients sebesar 0,207. Hal ini menunjukkan bahwa 
pengaruh Financial Attitude terhadap Financial Satisfaction adalah signifikan dengan arah positif Maka dari itu, dapat disimpulkan bahwa hipotesis pertama tidak ditolak.

Menunjukkan bahwa variabel Financial Behavior memiliki nilai t-statistik sebesar 8,869 yang lebih besar dari 1,96 dan nilai path coefficients sebesar 0,547. Hal ini menunjukkan bahwa pengaruh Financial Behavior terhadap Financial Satisfaction adalah signifikan dengan arah positif. Maka dari itu, dapat disimpulkan bahwa hipotesis kedua tidak ditolak.

Menunjukkan bahwa variabel Financial Knowledge memiliki nilai t-statistik sebesar 2,549 yang lebih besar dari 1,96 dan nilai path coefficients sebesar 0,139. Hal ini menunjukkan bahwa pengaruh Financial Knowledge terhadap Financial Satisfaction adalah signifikan dengan arah positif. Maka dari itu, dapat disimpulkan bahwa hipotesis ketiga tidak ditolak.

Menunjukkan bahwa variabel Risk Tolerance memiliki nilai t-statistik sebesar 1,393 yang lebih kecil dari 1,96 dan nilai path coefficients sebesar -0,053. Hal ini menunjukkan bahwa Risk Tolerance mempunyai arah yang negatif terhadap Financial Satisfaction. Maka dari itu, dapat disimpulkan bahwa hipotesis keempat ditolak.

\section{DISKUSI}

Pengaruh Financial Attitude terhadap Financial Satisfaction. Hasil penelitian ini menunjukkan bahwa Financial Attitude berpengaruh positif terhadap Financial Satisfaction. Sehingga dapat disimpulkan bahwa terdapat pengaruh positif Financial Attitude terhadap Financial Satisfaction. Indikator dari variabel Financial Attitude yang paling berpengaruh terhadap Financial Satisfaction adalah indikator dengan pernyataan bahwa individu melakukan pencatatan pendapatan dan pengeluaran. Hal ini disebabkan karena Financial Attitude (sikap keuangan) yang baik dapat dimiliki oleh individu jika dapat pencatatan pendapatan dan pengeluaran dengan baik dan rapi. Sehingga pengelolaan keuangan akan menjadi lebih baik dan kondisi keuangan akan menjadi lebih sehat yang selanjutnya dapat berdampak pada Financial Satisfaction (kepuasan keuangan) yang tinggi dari individu. Hasil penelitian ini sejalan dengan hasil penelitian yang dilakukan oleh Falahati et al. (2012), Chandra et al. (2015), serta Arifin (2017) yang menunjukkan bahwa terdapat pengaruh positif Financial Attitude terhadap Financial Satisfaction.

Pengaruh Financial Behavior terhadap Financial Satisfaction. Hasil penelitian ini menunjukkan bahwa Financial Behavior berpengaruh positif terhadap Financial Satisfaction. Sehingga dapat disimpulkan bahwa terdapat pengaruh positif Financial Behavior terhadap Financial Satisfaction. Indikator dari variabel Financial Behavior yang paling berpengaruh terhadap Financial Satisfaction adalah indikator dengan pernyataan bahwa individu tidak memiliki masalah keuangan karena memiliki cukup uang. Individu yang memiliki cukup uang akan merasa bahwa dirinya tidak memiliki permasalahan keuangan sehingga individu tersebut cenderung mempunyai Financial Satisfaction (kepuasan keuangan) yang tinggi. Hasil penelitian ini sejalan dengan hasil penelitian yang dilakukan oleh Joo et al. (2004), Falahati et al. (2012), serta Saurabh dan Nandan (2018) yang menunjukkan bahwa terdapat pengaruh positif Financial Behavior terhadap Financial Satisfaction.

Pengaruh Financial Knowledge terhadap Financial Satisfaction. Hasil penelitian ini menunjukkan bahwa Financial Knowledge berpengaruh positif terhadap Financial Satisfaction. Sehingga dapat disimpulkan bahwa terdapat pengaruh positif Financial Knowledge terhadap Financial Satisfaction.Indikator dari variabel Financial Behavior yang paling berpengaruh terhadap Financial Satisfaction adalah indikator dengan pernyataan bahwa individu mengetahui 
tentang suku bunga yang dikenakan oleh bank. Apabila individu mengetahui tingkat suku bunga bank, maka individu tersebut cenderung lebih mempunyai Financial Satisfaction yang lebih tinggi karena telah mendapat return yang diinginkan pada pilihannya. Hasil penelitian ini sejalan dengan hasil penelitian yang dilakukan oleh Joo et al. (2004), Saurabh et al. (2018), dan Arifin et al. (2018) yang menunjukkan bahwa terdapat pengaruh positif Financial Knowledge terhadap Financial Satisfaction.

Pengaruh Risk Tolerance terhadap Financial Satisfaction. Hasil penelitian ini menunjukkan bahwa tidak terdapat pengaruh Risk Tolerance terhadap Financial Satisfaction. Sehingga dapat disimpulkan bahwa tidak terdapat pengaruh Risk Tolerance terhadap Financial Satisfaction. Hasil penelitian ini sejalan dengan hasil penelitian yang dilakukan oleh Sahi dan Kalra (2013) yang menunjukkan bahwa tidak terdapat pengaruh Risk Tolerance terhadap Financial Satisfaction. Pada tingkat standar hidup seseorang untuk Risk Tolerance tidak dapat disamakan dengan tingkat kehidupan seseorang saat ini, dikarenakan tingkat Financial Satisfaction (kepuasaan keuangan) seseorang tidak memadai dengan jumlah tanggungan yang harus dipenuhi. Hasil dari penelitian ini berbeda dengan penelitian Jeong dan Hanna (2004) serta Pratiwi (2019) yang menunjukkan bahwa terdapat pengaruh Risk Tolerance terhadap Financial Satisfaction.

\section{Kesimpulan}

Berdasarkan hasil pembahasaan yang sudah dilakukan, maka dapat disimpulkan sebagai berikut, (1) Terdapat pengaruh positif Financial Attitude terhadap Financial Satisfaction. (2) Terdapat pengaruh positif Financial Behavior terhadap Financial Satisfaction. (3) Terdapat pengaruh positif Financial Knowledge terhadap Financial Satisfaction. (4) Tidak terdapat pengaruh Risk Tolerance terhadap Financial Satisfaction. Berdasarkan hasil penelitian ini, maka akan diberikan beberapa saran yang dapat diuraikan sebagai berikut, (1) Untuk penelitian selanjutnya, disarankan untuk mencoba menggunakan wilayah yang lain untuk pengambilan sampel agar dapat diperoleh hasil temuan penelitian yang lainnya yang dapat digunakan untuk melengkapi hasil temuan penelitian sebelumnya. (2) Untuk penelitian selanjutnya, disarankan untuk menambah jumlah responden sehingga hasil yang diperoleh dapat lebih mewakili populasi. (3) Untuk penelitian selanjutnya disarankan untuk menggunakan variabel-variabel independen lain yang diduga dapat menjelaskan Financial Satisfaction seperti Financial Capability, Financial Education, Financial Efficacy, dan Financial Socialization. (4) Bagi pemerintah, disarankan untuk mendorong dan membantu pihak akademisi dalam menjalankan kegiatan pengabdian kepada masyarakat berupa kegiatan penyuluhan pengelolaan keuangan (lebih spesifiknya mengenai pencatatan pendapatan dan pengeluaran) agar masyarakat dapat mengerti cara melakukan pencatatan pendapatan dan pengeluaran dengan baik sehingga masyarakat dapat melakukan pengelolaan keuangan dengan baik dan mempunyai kondisi keuangan yang sehat yang selanjutnya dapat berdampak pada Financial Satisfaction (kepuasan keuangan) masyarakat yang tinggi. (5) Bagi perusahaan, disarankan untuk melakukan program Corporate Social Responsibility dengan menyelenggarakan seminar-seminar yang dapat memberikan edukasi keuangan kepada masyarakat dan meningkatkan pengetahuan keuangan masyarakat sehingga diharapkan masyarakat dapat mengelola keuangan dengan baik dan selanjutnya masyarakat dapat mempunyai Financial Satisfaction (kepuasan keuangan) yang tinggi. 


\section{DAFTAR PUSTAKA}

Ahmad, K. A., Hasan, R., and Idris, F. (2017). Influence of Financial Literacy on Financial Satisfaction with Financial Behavior as Moderating Variable. Asian Journal of Technical Vocational Education and Training, 2, 1-9.

Ali, A., Rahman, M. S. A., \& Bakar, A. (2015). Financial Satisfaction and the Influence of Financial Literacy in Malaysia. Social Indicators Research, 120(1), 137-156.

Arifin, A. Z. (2017). The Influence of Financial Knowledge, Control and Income on Individual Financial Behavior. European Research Studies Journal, 20(3), 635-648.

Arifin, A. Z. (2018). Influence Factors toward Financial Satisfaction with Financial Behavior as Intervening Variable on Jakarta Area Workforce. European Research Studies Journal, 21(1), 90-103.

Candra, J. W., \& Memarista, G. (2015). Faktor-Faktor yang Mempengaruhi Financial Satisfaction pada Mahasiswa Universitas Kristen Petra. Finesta, 3(2), 1-6.

Chen, H., dan Volpe, R. P. 1998. “An Analysis of Personal Financial Literacy Among College Students". Financial Services Review, 7(2), 107-128.

Chowa, G. A., Despard, M., \& Akoto, I. O. (2012). Financial Knowledge and Attitudes of Youth in Ghana.

Diener, E., Oishi, S., \& Lucas, R. E. (2003). Personality, Culture, and Subjective Well-Being: Emotional and Cognitive Evaluations of Life. Annual Review of Psychology Journal, 54(1), 403-425.

Falahati, L., Sabri, M. F., \& Paim, L. H. (2012). Assessment a model of financial satisfaction predictors: Examining the mediate effect of financial behavior and financial strain. World Applied Sciences Journal, 20(2), 190-197.

Furnham, A. (1984). Many sides of the coin: The psychology of money usage. Personal and Individual Differences, 5(5), 501-509.

Gerrans, P., Campitelli, G., \& Speelman, C. (2013). The Relationship Between Personal Financial Wellness and Financial Well Being: A Structural Equation Modelling Approach. Journal of Family and Economic Issues, 5-44.

Hira, T. K., and Mugenda, O. M. (1998). Predictors of Financial Satisfaction: Differences Between Retirees and Non-retirees. Journal of Financial Counseling and Planning, 9(2), 75-84.

Jeong, Hanna (2004). Risk Tolerance and Financial Satisfaction. International Journal of Human Ecology, 5, 35-43.

Jogiyanto, (2007). Sistem Informasi Keperilakuan. Edisi Revisi. Yogyakarta: Andi Offset.

Joo, S., \& Grable, J. E. (2004). An Exploratory Framework of the Determinants of Financial Satisfaction. Journal of Family and Economic Issues, 25(1), 25-50.

Manulife Investor Sentiment Index Study (2016) "What is the Biggest Regret of Investors" at available

https://www.manulife.co.id/content/dam/insurance/id/id/documents/manulife-investorsentiment-index/Manulife_MISI10_4Feb2016.pdf.

Sindonews, (2020) "Menkeu Akui Pendapatan Masyarakat Kecil Turun Imbas Wabah Corona" at available at https://ekbis.sindonews.com/read/96010/33/menkeu-akui-pendapatanmasyarakat-kecil-turun-imbas-covid-19-1594303644.

OJK, (2019). "Siaran Pers Survei OJK 2019: Indeks Literasi Dan Inklusi keuangan Meningkat" at available at https://www.ojk.go.id. 
Pratiwi, O. (2019). Pengaruh Financial Knowledge, Financial Behavior, Financial Efficacy dan Risk Tolerance Terhadap Financial Satisfaction. JURNAL DINAMIKA MANAJEMEN DAN BISNIS, 2(2), 24-30.

Sahi, S. K., \& Kalra, S. K. (2013). Measuring Financial Risk taking using a dual preference approach for determination of Financial Satisfaction. Indian Institute of Management, Ahmedabad.

Saurabh, K., \& Nandan, T. (2018). Role of Financial Risk Attitude and Financial Behavior As Mediators In Financial Satisfaction. South Asian Journal of Business Studies, 7(2), 207224.

Xiao, J. J. (2015). Consumer Economic Well-being. USA: Springer New York. 